\title{
Equipment limitations of a multichannel infusion pump
}

\author{
Norbert Froese, MD $\cdot$ Jason McVicar, MD • \\ Mark Ansermino, MD
}

Received: 22 September 2010/Accepted: 24 September 2010/Published online: 15 October 2010

(C) Canadian Anesthesiologists' Society 2010

\section{To the Editor,}

We report a case involving a propofol overdose that was associated with intravenous anesthesia delivered by an Alaris ${ }^{\circledR}$ PC infusion system (Cardinal Health, San Diego, CA, USA). An infant weighing $4.5 \mathrm{~kg}$ underwent rigid bronchoscopy under general anesthesia. A total intravenous anesthetic was planned using remifentanil and propofol infusions for anesthetic maintenance. An Alaris PC 8015 infusion system, software version 9, equipped with two 8110 series syringe modules and one 8100 series infusion module, was used to deliver propofol, remifentanil, and intravenous fluid (Figure).

The pump had not been powered down following the previous case. This step was omitted to facilitate efficient use of time and to avoid the delay inherent in the pump's power-down and power-up sequence. During the programming of the syringe module delivering propofol, the operator scrolled through the page displaying the previous patient's weight and thereby programmed the module to deliver propofol at $300 \mathrm{ug} \cdot \mathrm{kg}^{-1} \cdot \mathrm{min}^{-1}\left(122.4 \mathrm{~mL} \cdot \mathrm{hr}^{-1}\right)$ based on the previous patient's weight of $68 \mathrm{~kg}$. This syringe module was set to pause, and the syringe module delivering remifentantil was subsequently programmed. In this case, the operator changed the patient's weight to 4.5 $\mathrm{kg}$ and programmed the module based on this weight to deliver a dose of $0.2 \mathrm{ug} \cdot \mathrm{kg}^{-1} \cdot \mathrm{min}^{-1}\left(5.4 \mathrm{~mL} \cdot \mathrm{hr}^{-1}\right)$. This

N. Froese, MD $(\bowtie) \cdot M$. Ansermino, MD

British Columbia's Children's Hospital, The University

of British Columbia, Vancouver, BC, Canada

J. McVicar, MD

Kingston General Hospital, Queen's University,

Kingston, ON, Canada syringe module was also set to pause. The infusion system gave no indication or warning that two attached modules were programmed with disparate weights with a more than tenfold difference between them.

The two drug infusions, together with a normal saline infusion, were connected to the patient's intravenous cannula and re-started. After approximately three minutes, the propofol dose was decreased to $200 \mathrm{ug} \cdot \mathrm{kg}^{-1} \cdot \mathrm{min}^{-1}$ (81.6 $\mathrm{mL} \cdot \mathrm{hr}^{-1}$ ) based on a weight of $68 \mathrm{~kg}$ in response to a decreased respiratory rate. Within four minutes, the attending anesthesiologist observed marked burst suppression on the bispectral index (BIS) monitor as well as the high infusion rate (in $\mathrm{mL} \cdot \mathrm{hr}^{-1}$ ) on the infusion pump. The propofol infusion was stopped, at which time a total of 130 $\mathrm{mg}$ or $29 \mathrm{mg} \cdot \mathrm{kg}^{-1}$ of propofol had been administered. Spontaneous respiration returned within $20 \mathrm{~min}$ and the procedure was completed successfully. The infant did not develop hypotension or bradycardia. He was awake within $45 \mathrm{~min}$ and made an uneventful recovery.

Although operator error was the primary cause of this event because the propofol module was programmed without altering the weight of the previous patient, we believe that this case highlights a safety concern regarding the Alaris PC infusion system for intravenous anesthesia delivery. This system requires a cumbersome power-off and power-on procedure to reset the unit and clear the previous patient's data. This limitation encourages the practice of not resetting the unit between cases during a busy surgical schedule. The system does not display the patient's weight during normal operation, which decreases the likelihood of detecting a weight programming error.

Most importantly, we are concerned that this device allows component modules to deliver drugs based on very different weights without providing any system alerts to the operator. We believe that this is an important safety 


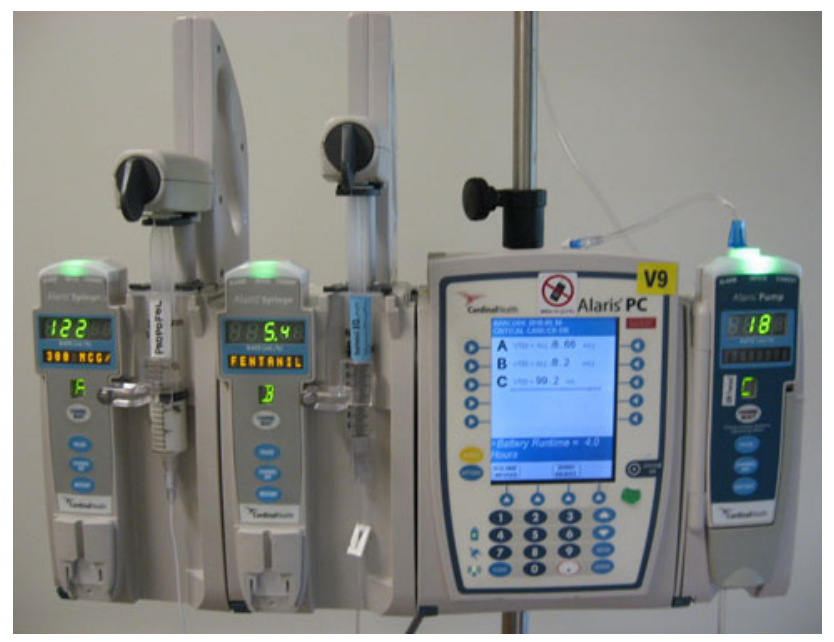

Figure Intravenous infusion system as configured for the case

concern whenever the Alaris PC infusion system is used in the operative or critical care settings.
Disclosures No funding sources supported this work. The authors have no commercial or non-commercial affiliations that are or may be perceived to be a conflict of interest with the work. The authors have no other associations, for example, consultancies.

Competing interests None declared. 